\title{
Further Evaluation of the SG Test Strip for Estimation of Urinary Osmolality ${ }^{1}$ )
}

\author{
By K. Dörner \\ Universitätskinderklinik Kiel \\ R. Campos \\ Department of Clinical Chemistry, University of Concepcion (Chile) and
}

\author{
Susanne Börnsen \\ Universitätskinderklinik Kiel
}

(Received October 27, 1983/February 9, 1984)

Summary: The mass densities of 2000 urines from children and 2000 urines from adults were determined with the new test strip, Multistix SG, and the results were compared with osmolality measurements. Normal urinary parameters were investigated for possible interference with the test strip reading. Variations in the $\mathrm{pH}$ and ionic composition of urine considerably influenced the test strip reading, whereas nonionic compounds, such as glucose and urea, showed practically no interference. For patients on a normal diet and without metabolic diseases, the new test strip is more appropriate than urometry for the determination of the mass density of the urine.

\section{Weitergehende Untersuchungèn zur Abschätzung der Urin-Osmolalität mit dem SG-Teststreifen}

Zusammenfassung: Bei 2000 Urinen von Kindern und bei 2000 Urinen von Erwachsenen wurde die Dichte des Urins durch den neuen Teststreifen Multistix SG bestimmt und mit den Ergebnissen der Osmometrie verglichen. Interferenzen der Teststreifenanzeige durch physiologische Urinbestandteile wurden ausführlich untersucht. Es ergab sich ein erheblicher Einfluß des Urin-pH und der ionalen Zusammensetzung auf das Teststreifenergebñis. Dagegen interferierten nichtionische Bestandteile wie Glucose und Harnstoff praktisch nicht. Die Dichte des Urins bei Patienten mit üblicher gemischter Kost und ohne Störungen im Säuren-BasenHaushalt kann mit dem neuen Teststreifen besser untersucht werden als mit der Urometrie.

\section{Introduction}

The urinary test strip Multistix SG includes a newly developed test field ("SG" stands for specific gravity $=$ mass density), which is useful for the estimation of urinary mass density. With regard to the reaction principle used (measurement of the ionic concentra-

1) Presented in part at the Joint Meeting of the German Society for Clinical Chemistry, the Austrian Society for Clinical Chemistry and the Austrian Society for Laboratory Medicine, Stuttgart, September 22-24, 1982. tion of strong cations) this field rather gives a description of the osmolal activity of the urine. Recently we published our initial results on the empirical correlation of the test strip indication (SG) and urinary osmolality (1). In the meantime, contradictory results $(2-8)$, based on a rather small number of urine samples, have been published. We now report a comprehensive evaluation, which defines more precisely the feasibility and limitations of the SG field. 


\section{Materials and Methods}

Urinary test strip Multistix SG, Miles/Ames, Frankfurt.

The urine samples consisted of 2000 urine specimen from adults (in-patients of the 1" Clinic, Medical School of the University of Kiel) and 2000 urine specimen from children of different ages (inand out-patients of the Children's Hospital, Medical School of the University of Kiel). All urine specimens from adults were sampled in the morning, those from children being sampled in the morning and before noon. Test strip examination and determination of osmolality were not performed later than 4-5 hours after sampling. An interpolation of test strip reading was recommended for the evaluators.

The results were registered, together with the $\mathrm{pH}$ value of the urine and the concentrations of glucose, protein and ketone bodies; blood, if present, was also determined. According to the recommendation of the manufacturer, the test strip result was adjusted to higher values by adding 0.005 (corresponding to 1 field) in all urines with a $\mathrm{pH} \geqslant 6.5$. All tests were performed by experienced technicians of the clinical laboratory. All samples with an obvious discrepancy between the test strip result and osmolality were kept frozen for further examination.

Urines that gave results outside the $80 \%$ range (68 adults, 96 children), and other urines showing values within the $80 \%$ range (76 adults, 101 children) (cf. results) were examined in more detail: $\mathrm{pH}$ (glass electrode), sodium and potassium (flame photometry), calcium and magnesium (atomic absorption spectrophotometry), chloride (coulometry), phosphate (ammonium molydate method), urea (acc. to Berthelot), uric acid (fully enzymatic aldehyde dehydrogenase method) and creatinine (Jaffé, kinetic assay). All routine methods were used under quality control supervision. Ammonia was determined according to Berthelot.

Interferences by certain cations and anions were examined in binary systems. For this' purpose isoosmolal solutions of sodium chloride and the salt to be examined were made with approximately the same $\mathrm{pH}$. These two solutions were mixed in dilution series: $10+0,9.5+0.5,9+1,8+2, \ldots$ etc.

Osmolality and test strip reaction were measured in duplicate.

\section{Results}

Correlations of SG test strip reading and osmolality in children and adults

The SG test field yields dubious results in urines with a $\mathrm{pH} \geqslant 8.0$, as will be shown later. Furthermore the SG field does not respond to glucose. Thus all urines with a $\mathrm{pH} \geqslant 8.0$ and a glucose concentration $\geqslant 1 \mathrm{~g} / 1$ were omitted from tables $1-3$ and figures $1-2$, which compare urinary osmolalities with the various classes of test strip response. These tables and figures include results for a total of 1815 children's and 1824 adults' urines.

To examine the correlation between SG test strip reading and osmolality a non-parametric and graphical approach was chosen. In the graphic presentation of figures 1 and 2 the osmolality percentile values $\mathrm{P}_{10}, \mathrm{P}_{50}$ and $\mathrm{P}_{90}$ of each test strip class are connected.

Account was taken in the graphic approximation of the fact that some classes were less frequently repre-

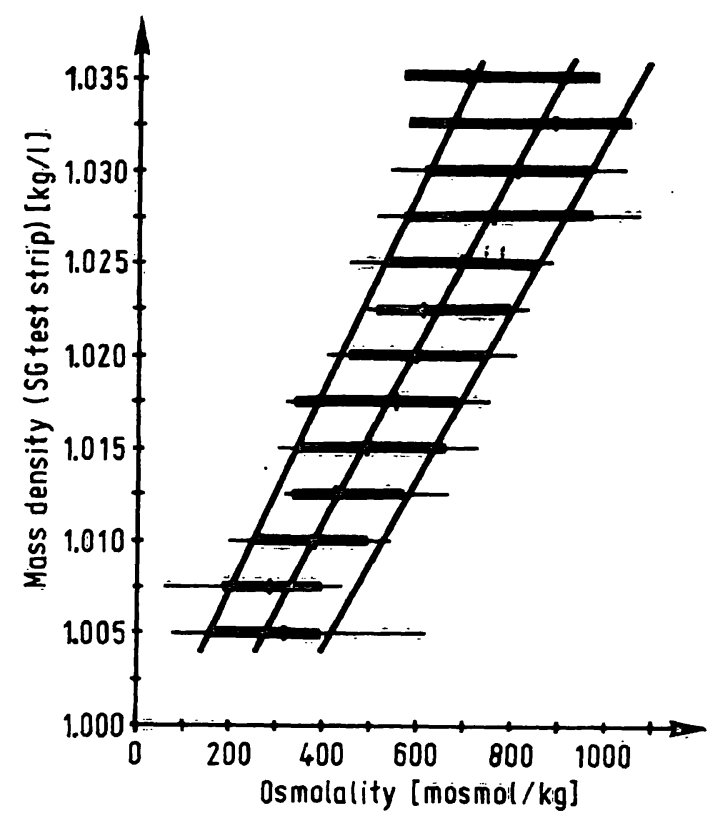

Fig. 1. Correlation of SG test strip reading and osmolality in adults. $P_{5}, P_{10}, P_{50}, P_{90}$, and $P_{95}$ of osmolality in the various test strip classes are given.

$\mathrm{P}_{10-90}$; $-\mathrm{P}_{5-95}$

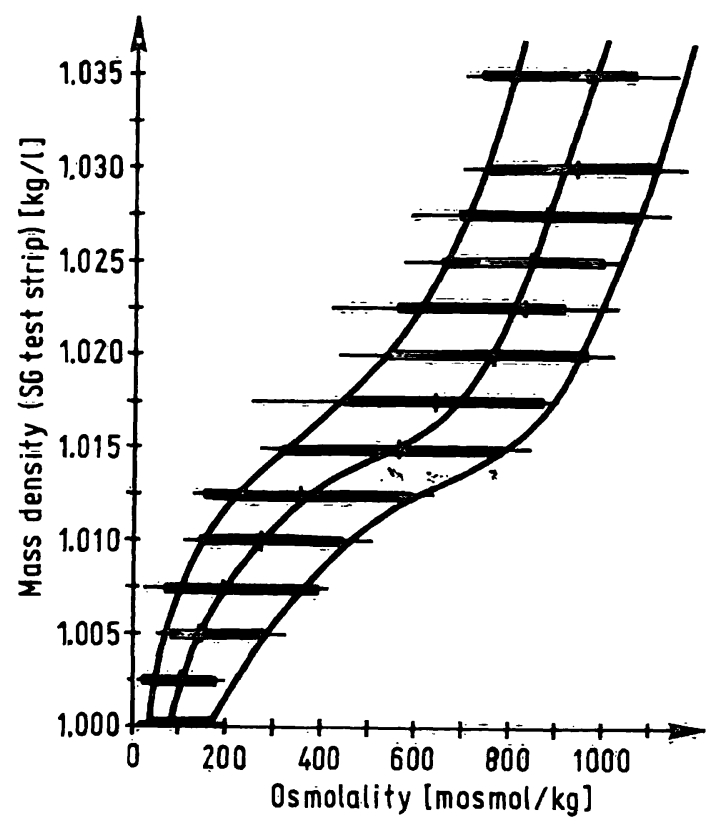

Fig. 2. Correlation of SG test strip reading and osmolality in children. $P_{5}, P_{10}, P_{50}, P_{90}$ and $P_{95}$ of osmolality in the various test strip classes are given.

$P_{10-90 ;} \longrightarrow P_{5-95}$

sented (e.g. 1.0175 and $1.0225 \mathrm{~kg} / \mathrm{l}$ ) than the main classes. The correlation lines show a sigmoidal shape in children, and a linear correlation in adults.

There are obvious differences between the results seen in children and adults. Children's urines more often have osmolalities below $400 \mathrm{mosmol} / \mathrm{kg}$ and these urines render a higher test strip reading than comparable urines of adults. In the range of medium urine concentration (SG test strip reading 1.015 and 
Tab. 1. Percentiles of osmolalities measured in the different SG test strip reading classes $1.000-1.035$. Corresponding values of adults and children are given.

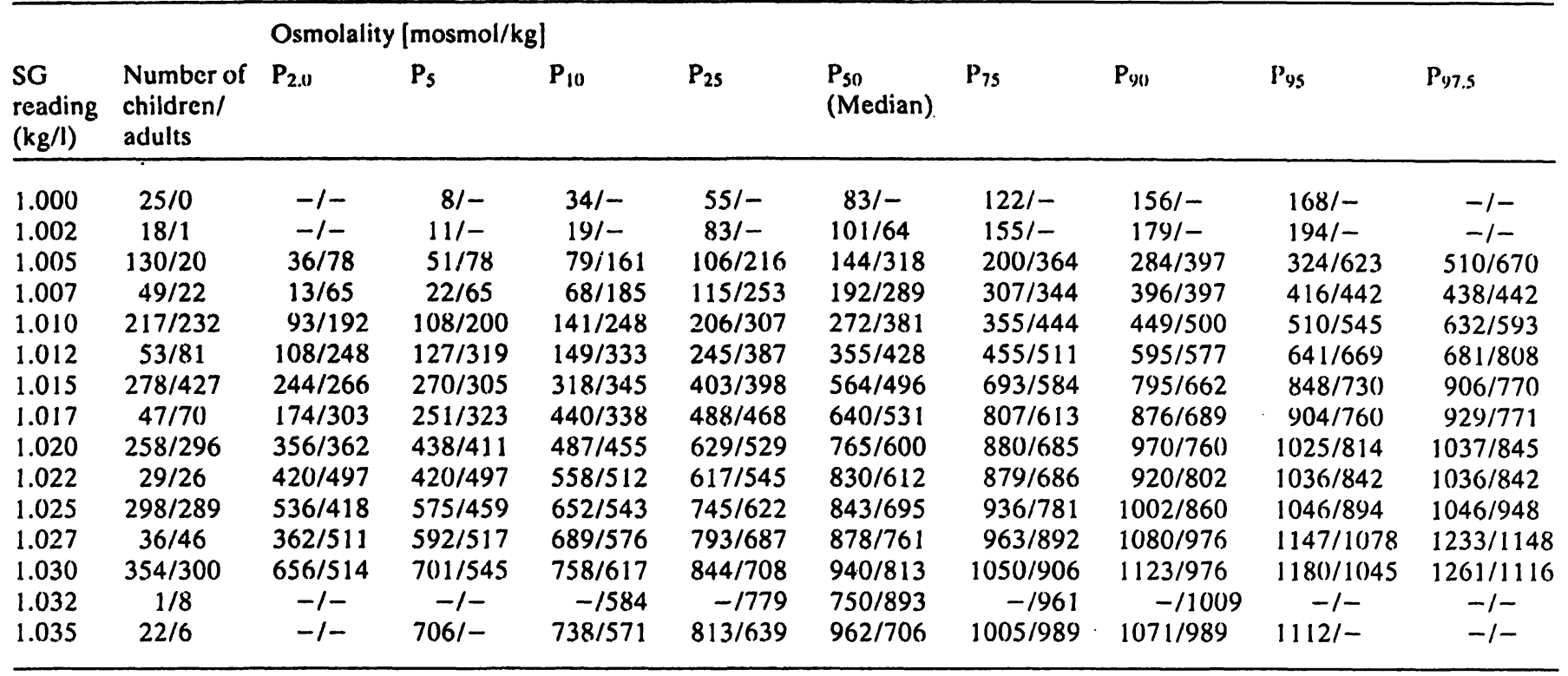

Tab. 2. Percent frequency of osmolality results ( 7 classes) in the various test strip reading classes: adults' data.

\begin{tabular}{|c|c|c|c|c|c|c|c|c|}
\hline \multirow[b]{2}{*}{$\begin{array}{l}\text { SG reading } \\
(\mathrm{kg} / \mathrm{l})\end{array}$} & \multirow[b]{2}{*}{$\mathbf{n}$} & \multicolumn{7}{|c|}{ Frequency $(\%)$ in osmolality (mosmol/kg) classes } \\
\hline & & -200 & -400 & -600 & -800 & -1000 & -1200 & -1400 \\
\hline 1.035 & 6 & - & - & 16.7 & 33.3 & 33.3 & 16.7 & - \\
\hline 1.0325 & 8 & - & - & 12.5 & 12.5 & 50.0 & 25.0 & - \\
\hline 1.030 & 300 & - & 0.7 & 8.3 & 38.3 & 44.3 & 8.3 & - \\
\hline 1.0275 & 46 & - & - & 13.0 & 45.7 & 30.4 & 6.5 & 4.3 \\
\hline 1.025 & 289 & - & 2.1 & 20.1 & 57.1 & 19.7 & 1.0 &.- \\
\hline 1.0225 & 26 & - & - & 46.2 & 38.5 & 11.5 & 3.8 & - \\
\hline 1.020 & 296 & - & 4.4 & 46.3 & 42.6 & 6.4 & 0.3 & - \\
\hline 1.0175 & 70 & - & 12.9 & 58.6 & 25.7 & 2.9 & - & - \\
\hline 1.015 & 427 & 0.2 & 25.5 & 52.0 & 20.8 & 1.2 & 0.2 & - \\
\hline 1.0125 & 81 & - & 32.1 & 59.3 & 4.9 & 3.7 & - & - \\
\hline 1.010 & 232 & 5.2 & 55.6 & 36.6 & 2.2 & 0.4 & - & - \\
\hline 1.0075 & 22 & 9.1 & 81.8 & 9.1 & - & - & - & - \\
\hline 1.005 & 20 & 15.0 & 75.0 & - & 10.0 & - & - & - \\
\hline 1.0025 & 1 & 100 & - & - & - & - & - & - \\
\hline 1.000 & 0 & - & - & - & - & - & - & - \\
\hline
\end{tabular}

Tab. 3. Percent frequency of osmolality results ( $\overline{7}$ classes) in the various test strip reading classes: children's data.

\begin{tabular}{|c|c|c|c|c|c|c|c|c|}
\hline \multirow[b]{2}{*}{$\begin{array}{l}\text { SG reading } \\
(\mathrm{kg} / \mathrm{l})\end{array}$} & \multirow[b]{2}{*}{$\mathbf{n}$} & \multicolumn{7}{|c|}{ Frequency $(\%)$ in osmolality (mosmol/kg) classes } \\
\hline & & -200 & -400 & -600 & -800 & -1000 & -1200 & -1400 \\
\hline 1.035 & 22 & - & - & - & 22.7 & 45.5 & 31.8 & - \\
\hline 1.0325 & 1 & $-\cdot$ & - & - & 100 & - & - & - \\
\hline 1.030 & 354 & 0.3 & - & 1.1 & 13.3 & 48.3 & 33.1 & 4.0 \\
\hline 1.0275 & 36 & - & 2.8 & 2.8 & 2.0 & 55.6 & 13.9 & 0.6 \\
\hline 1.025 & 298 & - & 0.7 & 5.4 & 31.5 & 51.7 & 9.7 & 1.0 \\
\hline 1.0225 & 29 & - & - & 17.2 & 24.1 & 51.7 & 6.9 & - \\
\hline 1.020 & 258 & - & 3.5 & 15.9 & 38.4 & 34.9 & 7.4 & - \\
\hline 1.0175 & 47 & 2.1 & 6.4 & 31.9 & 27.7 & 31.9 & - & - \\
\hline 1.015 & 278 & 1.1 & 23.4 & 37.1 & 28.8 & 9.0 & 0.7 & - \\
\hline 1.0125 & 53 & 17.0 & 45.3 & 30.2 & 7.5 & - & - & - \\
\hline 1.010 & 217 & 22.6 & 57.6 & 16.6 & 2.8 & - & 0.5 & - \\
\hline 1.0075 & 49 & 53.1 & 36.7 & 10.2 & - & - & - & - \\
\hline 1.005 & 13 & 75.4 & 20.8 & 1.5 & 2.3 & - & - & - \\
\hline 1.0025 & 18 & 100 & - & - & - & - & - & - \\
\hline 1.000 & 25 & 100 & - & - & - & - & - & - \\
\hline
\end{tabular}


$1.020 \mathrm{~kg} / \mathrm{l})$ corresponding percentiles of osmolality are higher in children than in adults and they cover a broader range. Studying the age-specific differences of children's samples the well known fact that most urines of newborns and infants are found in the SG test strip reading range $\leqslant 1.015 \mathrm{~kg} / \mathrm{l}$ and those of older children in the SG test strip reading classes $\geqslant 1.015 \mathrm{~kg} / \mathrm{l}$ was confirmed. But an age dependency of the correlation of SG test strip reading and osmolality can not be derived.

The urines of children and adults were tested simultaneously by the same technicians and the same methods. Therefore the different results in children's and adults' urine specimens are due to their different compositions. The urines which we examined in more detail showed a higher total anion related phosphate excretion. Furthermore the mean quotient

$$
\frac{\sum\left[\mathrm{NH}_{4}^{+}\right]+\left[\mathrm{Na}^{+}\right]+\left[\mathrm{K}^{+}\right]}{\text {osmolality }}
$$

is higher in children than in adults. This is especially evident in the low SG test strip reading classes.

Finally the urines of children have significantly higher $\mathrm{pH}$ values than those of adults with the exception of extreme SG test strip reading classes (fig. 3 ).

The effects of $\mathrm{pH}$, concentration of cations and the phosphate concentration (both relative to osmolality) may have an additive effect, resulting in different correlations of SG test strip reading and osmolality in children and adults.

At the very beginning of this study it was noticed that strongly alkaline urines showed extremely low SG test strip readings in comparison with the osmolality measured. Our large number of data confirms the strong influence of urine $\mathrm{pH}$ values $\geqslant 8.0$ on the SG test strip reading. Urine values derived from samples with $\mathrm{pH} \simeq 5$ are equally distributed around the $\mathrm{P}_{50}$ osmolality values of each corresponding test strip class, i.e. these urines present neither SG field enhancement nor depression.

In those few cases where the urine $\mathrm{pH}$ value was below 5 , the SG test strip reading was always too high.

The manufacturer of the SG strip recommends a correction of the readings for alkaline urines (c.f. methods). To evaluate this correction we compared the $\mathrm{pH}$ of samples with the osmolality in single $S G$ test strip reading classes.

Figure 4 for example shows the urinary osmolalities of the children's samples with SG test strip reading = $1.015 \mathrm{~kg} / \mathrm{l}$. These samples are classified according to

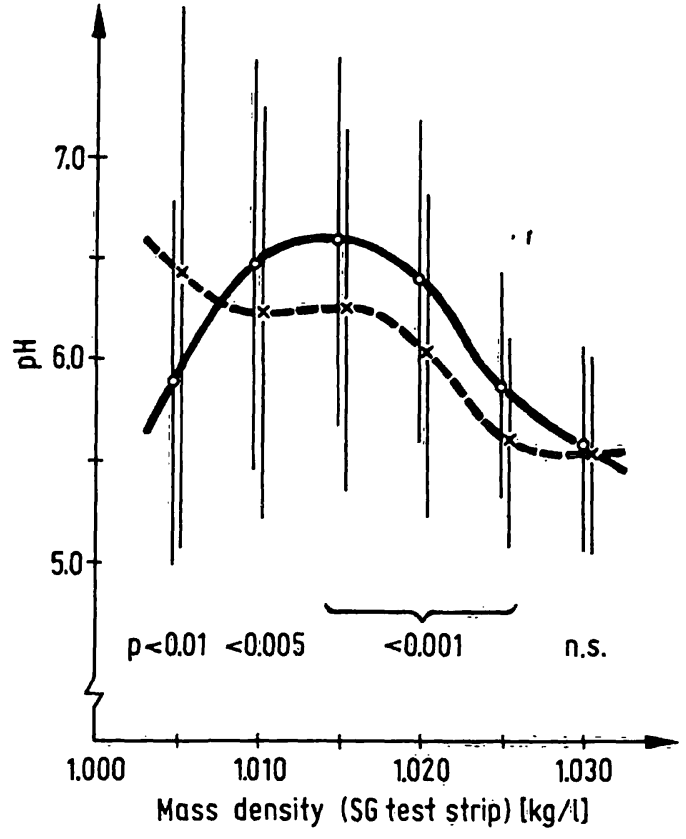

Fig. 3. Mean and standard deviation of urinary $\mathrm{pH}$ of children $(O)$ and adults $(x)$ in various $S G$ test strip reading classes. Statistical significant differences between children and adults were found by Student's t-test (n.s. = not significant).

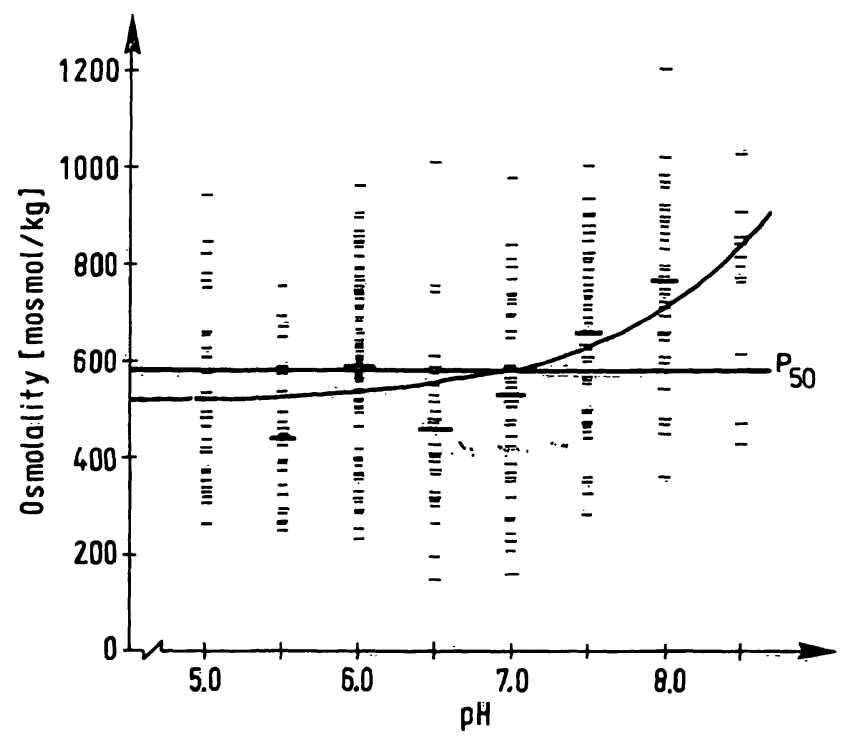

Fig. 4. Distribution of osmolality values in the SG test strip reading class 1.015 (children) in dependency on the urinary $\mathrm{pH}$. The short lines show the individual values, the stronger lines the arithmetic means and the long line the $\mathrm{P}_{50}$ value of all values. $y=512.8+0.06643 \cdot e^{x}$

their pH. Figure 4 gives the osmolalities in these subclasses, their mean value and the mean of the total group ( $587 \mathrm{mosmol} / \mathrm{kg}$ ). It may be seen that

a) urines with a $\mathrm{pH} \geqslant 8.0$ are in the wrong class, in spite of the correction, as their mean is rather high.

b) urines with pH of 7.0 and 7.5 are "correctly" classified

c) most urines with a pH of 6.5 may enter a falsely high class due to the correction, i. e. the correction is unnecessary. 
Influence of the ionic composition of urine on the $S G$ test strip reading

The test principle of the SG test field consists of release of $\mathrm{H}^{+}$-ions from a polymer by strong cations followed by detection of $\mathrm{H}^{+}$by a $\mathrm{pH}$ indicator. This $\mathrm{H}^{+}$-release is proportional to the osmolal activity of cations in the urine.

Obviously this procedure is enhanced by the anions phosphate and citrate, and the cations $\mathrm{NH}_{4}^{+}, \mathrm{Ca}^{2+}$ and $\mathrm{Mg}^{2+}$ are more effective than $\mathrm{Na}^{+}$and $\mathrm{K}^{+}$. This is demonstrated by figure 5 for $\mathrm{NH}_{4}^{+}$and phosphate. If sodium chloride (" $A$ ") and ammonium chloride (" $B$ ") solutions of isoosmolal activity (300 mosmol/ $\mathrm{kg}$ ) are mixed in increasing ratios as shown in the right part of figure 5 , the resulting osmolality is constant, but there is a minimal increase in SG test strip reading proportional to $\mathrm{NH}_{4}^{+}$concentration. $\mathrm{Ca}^{2+}$ and $\mathrm{Mg}^{2+}$ show an analogous effect, $\mathrm{K}^{+}$does not. Phosphate, in contrast to chloride, enhances the SG test strip reading (upper part of fig. 5):

$\begin{array}{lll}\begin{array}{l}\mathrm{NaCl} \\ \text { volume fraction }\end{array} & \begin{array}{l}\mathrm{NaH}_{2} \mathrm{PO}_{4}, \\ \text { volume fraction }\end{array} & \begin{array}{l}\mathrm{SG} \text { test } \\ \mathrm{kg} / \mathrm{l}\end{array} \\ 1.00 & 0 & \\ 0.75 & 0.25 & 1.005 \\ 0.50 & 0.50 & 1.015 \\ 0.25 & 0.75 & 1.025 \\ 0 & 1.00 & 1.028 \\ & & 1.030\end{array}$

Figure 5 demonstrates the relations in a quaternary system of $\mathrm{NaCl}, \mathrm{NaH}_{2} \mathrm{PO}_{4}, \mathrm{NH}_{4} \mathrm{Cl}$ and $\mathrm{NH}_{4} \mathrm{H}_{2} \mathrm{PO}_{4}$. This figure enables a prediction of the SG test strip reading in any mixture of these four salt solutions.

The sum of the straight lines $\overline{\mathrm{B}^{\prime} \mathrm{X}}+\overline{\mathrm{A}^{\prime} \mathrm{X}}+\overline{\mathrm{C}^{\prime} \mathrm{X}}+\overline{\mathrm{C}^{\prime} \mathrm{X}}$ may be designated as $\Sigma$.

The mixture at point $X$ contains $\frac{\overline{B^{\prime} X}}{\Sigma}$ parts $B+\frac{\overline{A^{\prime} X}}{\Sigma}$ parts $A+$ $\overline{\frac{C^{\prime} X}{\Sigma}}$ parts $C+\frac{\overline{D^{\prime} X}}{\Sigma}$ parts $D$.

The SG test strip reading at this point is $1.015 \mu \mathrm{g} /$, the osmolality of the whole system $300 \mathrm{mosmol} / \mathrm{kg}$.

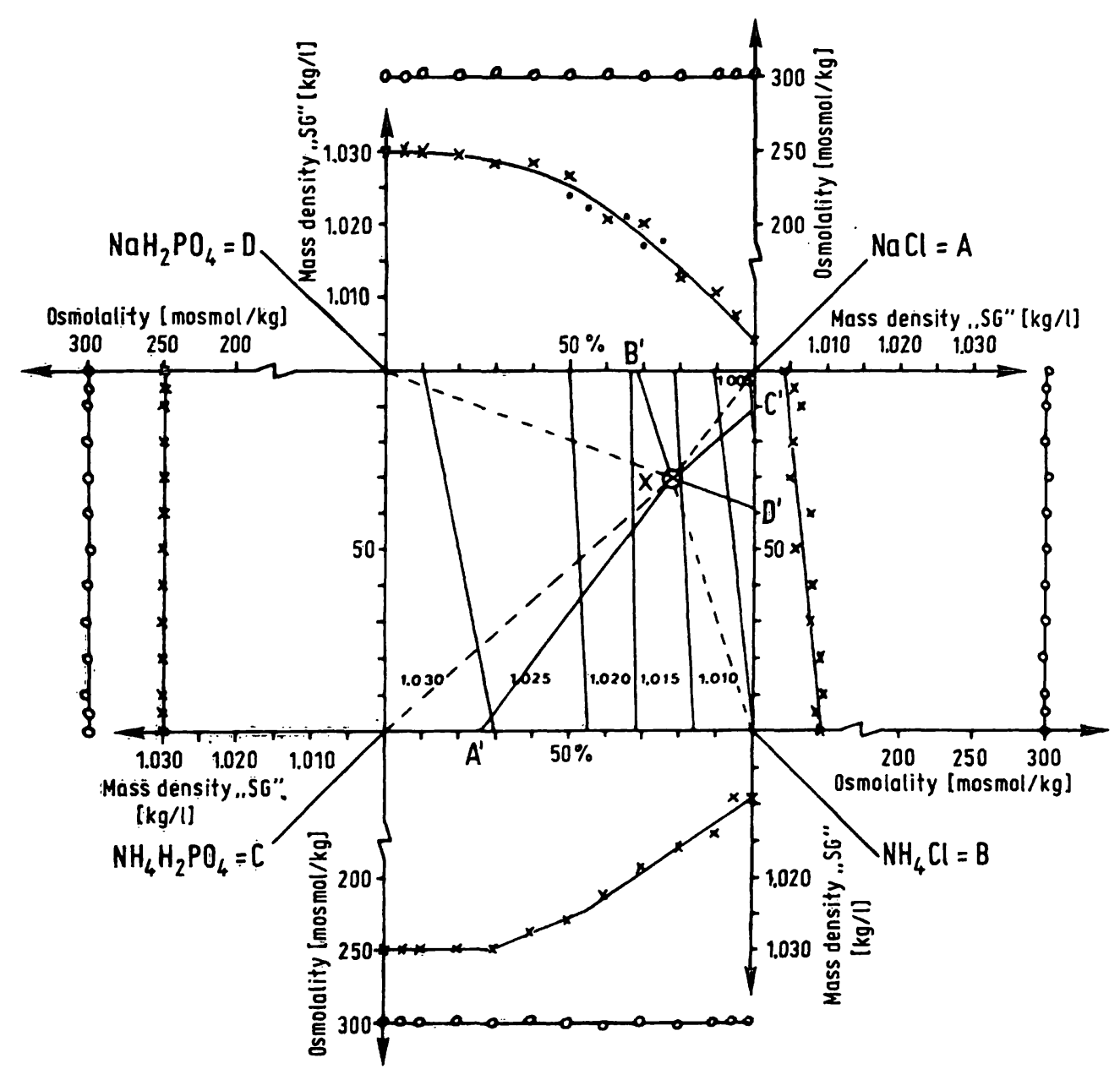

Fig. 5. Quaternary system of $\mathrm{NaCl}, \mathrm{NH}_{4} \mathrm{Cl}, \mathrm{NH}_{4} \mathrm{H}_{2} \mathrm{PO}_{4}$ and $\mathrm{NaH}_{2} \mathrm{PO}_{4}$ for the demonstration of the ionic influence on $\mathrm{SG}$ test strip reading. The outer four diagrams show the dependency of SG test strip reading (mass density "SG") in mixtures of two solutions. All solutions have the same osmolality of $300 \mathrm{mosmol} / \mathrm{kg}$ and $\mathrm{pH} 5.4$. SG test strip readings were performed by several persons, and their mean values are shown. The inner part of the figure, which was constructed with the aid of the outer diagrams, allows an estimation of SG: test strip reading in mixtures of these four solutions (c.f. results). 
In an analogous way the strong enhancement of citrate was proven. Acetate, lactate, urate, oxalate and sulphate caused no deviations compared with the results obtained with chloride. Hydrogen carbonate could not be examined, because of the erroneous SG test strip readings at $\mathrm{pH} 8.3\left(\mathrm{NaHCO}_{3}\right)$.

Influence of the nonionic composition of urine on the $S G$ test strip reading

Nonionic constituents of urine, such as glucose, urea and creatinine, do not directly affect the SG test field; the concentrations of these compounds exert an empirical influence on the correlation, mass density/osmolality.

Thus, urines with highly abnormal concentrations of these substances (relative to total osmolality) give "false" SG test strip readings. A concentration of 1.8 $\mathrm{g} / \mathrm{g}$ glucose equals $10 \mathrm{mosmol} / \mathrm{kg}$, and $18 \mathrm{~g} / \mathrm{l}$ glucose equals $100 \mathrm{mosmol} / \mathrm{kg}$. From the urinary osmolalities of table 1 , it is obvious that only a very strong glucosuria (detectable by the glucose field of Multistix SG), together with a low osmolality, causes wrong SG test field readings.

In the samples submitted to more detailed study, the proportion of urinary osmolality due to urea varied between 20 and $60 \%$. In very few cases extremly low or high urea concentrations were accompanied by inaccurate SG test strip readings.

The urinary creatinine concentrations are too low to influence the SG test strip reading.

Protein concentrations $\geqslant 1 \mathrm{~g} / 1$ cause a tendency to higher SG test strip readings, yet nearly all results were in the $80 \%$ range of the osmolalities in the corresponding test strip classes.

In contrast to protein, ketone bodies cause lower SG test strip readings, but these also were mostly within the $80 \%$ range.

\section{Discussion}

The new SG test field was developed for the semiquantitive estimation of urinary mass density. The reference method used was refractometry of total solids, a method which is seldom used in Europe. Several factors support the principle of measuring the performance of the SG test field by osmolality rather than by refractometry:

1) The physiologically important parameter for the assessment of renal concentrating ability is the osmotic pressure of the urine.
2) Urometry and refractometry are imprecise methods susceptible to interferences.

3) The test principle of the SG test field resembles more closely osmometry than urometry or refractometry.

The correlation of SG test strip reading and osmometry (tab. 1) is worse than that for any other semiquantitative test strip and a corresponding quantitative measurement. The $90 \%$ range of osmolalities in children is even broader than in adults. Other authors (4) reported similar results. We would like to stress two points:

1) Our unselected material was received from patients of all ages, with different diagnoses and various forms of therapy. It was a classical field study.

2) The SG test field reacts with $1 / 3$ of the osmotically active urinary constituents, the others contributing only empirically to the SG test strip reading.

We do not know exactly which diseases and which nutritional effects influence this empirical correlation. It may well be possible that more homogeneous random samples would result in a more defined $90 \%$ range.

Interference by several urinary constituents has been shown. Strongly alkaline and strongly acidic urines ( $\mathrm{pH}>8.0$ and $<4.9$ ) are not suitable for readings with the SG test field. Urines of patients with bacterial urinary tract infections, with severe disturbances of acid base balance and possibly with extreme nutritional habits (rich in vegetables: alkaline urine, rich in proteins, in particular meat: acid urine) should not be examined by the SG test strip.

Strongly alkaline urine may easily be recognized by the $\mathrm{pH}$ test field which is part of the Multistix SG. Thus the number of samples suitable for Multistix SG testing is decreased. We do not feel that this is a substantial limititation of efficacy.

Concerning the $\mathrm{pH}$-corrected SG test strip readings in urine $\geqslant 6.5$, which is recommended by the manufacturer, this seems unnecessary, provided that all urines $\geqslant 8.0$ are no longer tested.

Phosphate anions have a strong enhancing effect on SG test strip reading as shown in figure 5 . In our experience, high phosphate concentrations mostly parallel high osmolality, i.e. the empirical correlation of SG test strip reading and osmolality is maintained. 
On a diet composed mainly of milk and vegetables, in patients with hyperparathyreoidism and in general in children a relatively high urinary phosphate concentration may be found, resulting in a falsely elevated SG test strip reading. Of all the anions tested, only citrate resembles phosphate (cf. results) in causing a disproportionally high SG test strip reading. Normally the urinary citrate concentration is much lower than the phosphate concentration. In alkaline urines, however, the output may be $20-30 \mathrm{~g} /$ day $(=100$ $\mathrm{mmol} / \mathrm{d}$ ) (9). The influences of alkaline urine and high citrate excretion on SG test strip reading are adverse and perhaps may neutralize each other.

Nonionic urinary constituents present in relevant concentrations are glucose and urea. Neither of these need be responsible for actual interference because strong glucosuria is easily detected by the glucose test field, and high urea concentrations are mostly found in urines with high alkali ion concentrations.

In a few cases, a diet rich in protein and poor in salt (3) may yield wrong SG test strip results.

The different findings in children and adults are not fully explained by our results. The differences in urinary $\mathrm{pH}$ values, relative phosphate concentrations and other unknown factors may be interrelated with each other.

\section{References}

1. Dörner, K., Röhreke, E. \& Gustmann, H. (1982) Är̆ztl. Lab. 28, 153-156.

2. Burkhardt, A. E., Johnston, K. G., Waszak, C. E., Jackson, C. E. \& Shafer, S. R. (1982) Clin. Chem. 28, 2068-2072.

3. Kutter, D. \& Holtzmer, M. (1982) Med. Lab. 35, 41-44.

4. Frew, A. J., McEwan, J., Bell, G., Heath, M. \& Knapp, M. S. (1982) Br. Med. J. 285, 1168-1170.

5. Jamison, R. L. \& Robertson, C. R. (1982) Lancet II, 13961397.
A final assessment of the SG test field is not easy. It can never be characterized as a semiquantitative test for urinary osmolality. The manufacturer has outlined this product for estimation of urinary mass density. We did not compare the SG test field with urometry and we do not feel that this is worthwhile. In view of the well known systematic faults in daily ward work, the practicability of a test strip represents an enrichment of the diagnostic spectrum of urinary analysis for those patients with "normal" diet and "normal" metabolic condition. Preliminary results furthermore show that daily monitoring of intensive care patients may well be done within a constant and narrow range of error. Finally the SG test field integrated into a multi-field test strip opens a new dimension in semiquantitive urine analysis, because the content of glucose and protein, for example, should not be considered without additional information on the concentration of the tested urine.

\section{Acknowledgement}

The use of the computer facilities of the Department of Paediatric Cardiology (Direktor: Prof. Dr. Heintzen), Kiel University, School of Medicine, for the statistical calculations is gratefully acknowledged.
6. Zack jr., J. F. (1983) Clin. Chem. 29, 210-211

7. Kreib, D., Harrigan, T. D., Liakeas, P. \& Portnoy, A. L. (1983) Clin. Chem. 29, 1263-1264 (Abstr.).

8. Maturen, A., Nice, A. \& Williams, R. H. (1983) Clin. Chem. 29, 1259 (Abstr.)

9. Free, A., personal communication.

PD Dr. Dr. K. Dörner Universitätskinderklinik Schwanenweg 20 D-2300 Kiel 1 
. 